\section{Theories in collision}

\author{
Anthony Hallam
}

The Mass-Extinction Debates: How Science Works in a Crisis. Edited by William Glen. Stanford University Press: 1994. Pp. 370. \$49.50, £35 (hbk); \$17.95, $£ 12.95$ ( $p b k$ ). Distributed outside North America by Cambridge University Press.

IN recent years Bill Glen has established himself as a leading figure in what may be described as history of science on the hoof; his crucial piece of equipment is his tape recorder. Following the success of The Road to Jaramillo, his esteemed study of the plate-tectonics revolution, he has turned his attention to the massextinction controversies, which stemmed from the publication of a seminal paper by Luis Alvarez and colleagues in Science nearly a decade and a half ago. A limitation of Glen's earlier study was that he interviewed the principal Earth scientists many years after their important research, so he had to cope with their selective memories and retrospective rationalizations.

By involving himself from the beginning of the mass-extinction debates, Glen has this time avoided such difficulties. $\mathrm{He}$ intends to write a book on the subject and the first two chapters of this volume are evidently a precis. Judging by their quality, his full-scale book is likely to be as well received as his earlier work. The first chapter is an excellent review of the rival extraterrestrial-impact and terrestrial-volcanic theories argued for the mass extinction at the end of the Cretaceous period ( 65 million years ago), and of various outcomes such as the claim for an extinction periodicity, which aroused the interest of several astronomers. The second chapter on "how science works" deals with personal and institutional factors, such as how attitudes to impact and catastrophic events were influenced by scientific discipline, with, for instance, scientists with a strong physical or chemical background being far more sympathetic than palaeontologists, who had greater knowledge of the biological data.

\section{Media involvement}

The rest of the book is the outcome of a meeting held in Illinois more three years ago, with a number of contributions varying considerably in quality: in other words, the usual curate's egg. Some are slight, others substantial, some lucid, others, such as Herbert Shaw's, opaque and jargon-ridden; but all in all they give a representative sample of the range of attitudes expressed during the debate. One of the most interesting is by Elizabeth Clemens, a sociologist who makes a plausible case that media involvement relating to the public's fascination with dinosaurs has driven the debate to a considerable extent. Several Earth scientists who favour impact theories, namely Ken Hsü, Digby McLaren and David Raup, consider that the general resistance of their colleagues to the Alvarez hypothesis, at least initially, was due to their having been indoctrinated with an outdated Lyellian uninformitarianism, which denied the possibility of catastrophic happenings. To which one is tempted to reply, recalling Scoop, Evelyn Waugh's delightful novel about journalism, "Up to a point, Lord Copper." If one defines a catastrophic mass extinction as one in which a significant proportion of the Earth's biota becomes extinct in a geologically insignificant period of time, say less than a few thousand years, then it is perfectly possible to believe in such events without necessarily invoking asteroids or comets.

It all depends on the evidence, and only for the mass extinction at the end of the Cretaceous has a strong case been made for impact at that time, in terms of significant iridium anomalies on a global scale, shocked minerals and other data. For all other mass-extinction events, major or minor, the evidence is either ambiguous, inconclusive or nonexistent. In these circumstances, to accept in the absence of supporting evidence impact events as a general cause of mass extinctions, a view evidently favoured by Victor Clube and Shaw, seems to fall in the realm of faith rather than science. Hsü and Shaw invoke fractal geometry, nonlinear dynamics and chaos theory. While it is perfectly true that, as Hsü states, the pattern of natural temporal change shows that the frequency of occurrence of natural processes is inversely related to their magnitude, a phenomenon readily apparent with both floods and earthquakes, and well expressed in Raup's notorious "kill curve", this says nothing about the causal factors.

The 'catastrophists' are very well represented in this book. At the other extreme, John Briggs expresses a more traditional view of extinctions as extended over considerable periods of time, and very rarely of global extent. John Van Valen contributes a thoughtful essay on the relation of extinction to selection and unsurprisingly, as the author of the celebrated Red Queen hypothesis, rejects the view increasingly held by palaeontologists that displacive competition by laterevolved "biologically superior" organisms, as favoured by Darwin, is of far less significance in evolutionary history than preemptive competition by the incumbents of given ecological niches. Only when extinction wipes out these incumbents can other organisms opportunistically respond. So no one seriously argues any more that the dinosaurs died out because of competition from the mam- mals, with whom they had coexisted through most of the Mesozoic.

One of the most illuminating parts of the book is a couple of interviews by Glen of prominent palaeontologists identified with opposing camps, and who thus present contrasting views. Bill Clemens expresses a balanced, reasonable and well informed scepticism towards the impact hypothesis as an explanation for the extinction of dinosaurs, whereas Steve Gould was converted to the hypothesis fairly early on. Gould is determined, however, to dissociate belief in impact as a cause of mass extinction from his views on punctuated equilibria, a link that Glen persistently tries to establish.

\section{New evidence}

So where do we stand today? In the past few years, belief in a bolide impact at the end of the Cretaceous has been strengthened by new discoveries, most notably those related to an apparently huge buried impact crater in the Yucatan Peninsula of Mexico. Although the new evidence is impressive, scepticism is bound to persist in some informed circles at least until one or more new boreholes are drilled to establish the precise age of the oldest sedimentary strata overlying the purported impact debris. This is necessary in order to refute a counter claim by a US oil geologist who worked on the site in the $1960 \mathrm{~s}$ that several hundred metres of Upper Cretaceous limestone overlie what he and others have interpreted as volcanic rock. But even if one accepts that an impact is conclusively established for the end of the Cretaceous, argument will surely persist about the causal factors of the mass extinction. The earlier 'Dante's Inferno' ideas involving drastic falls or rises of temperature, or both, and acid rain and wild fires on a massive scale, seems far too drastic to account for the selective nature of the extinctions, at least on the continents. It is surprising that so little attention is paid in the book to such factors as Earth-bound climatic and sealevel changes, for there is no reason why these could not also be catastrophic in character on rare occasions. Certainly as a model for mass extinctions in general, they carry greater plausibility than impact events, because they have abundant supporting evidence. As regards sea level, the spread of anoxic bottom waters associated with rapid marine transgressions seems to be a more important factor than the more widely cited regressions. This is indeed likely to be the case for the biggest mass extinction event of all, at the end of the Permian, which, contrary to a widely held belief, evidently had a considerable catastrophic component.

Anthony Hallam is in the School of Earth Sciences, University of Birmingham, Birmingham, B15 2TT, UK. 